\title{
Assessing Seismic Performance of Gantry Crane Subjected to Near-Field Ground Motions Using Incremental Dynamic and Endurance Time Analysis Methods
}

\author{
Qihui Peng $\mathbb{D}^{1,2}$ Wen-ming Cheng $\mathbb{D}^{1,2}$ Peng Guo $\mathbb{D}^{1,2}$ and Hongyu Jia $\mathbb{D}^{3}$ \\ ${ }^{1}$ School of Mechanical Engineering, Southwest Jiaotong University, Chengdu 610031, China \\ ${ }^{2}$ Technology and Equipment of Rail Transit Operation and Maintenance Key Laboratory of Sichuan Province, \\ Chengdu 610031, China \\ ${ }^{3}$ School of Civil Engineering, Southwest Jiaotong University, Chengdu 610031, China
}

Correspondence should be addressed to Qihui Peng; bk20100219@my.swjtu.edu.cn, Wen-ming Cheng; wmcheng@swjtu.edu.cn, Peng Guo; pengguo318@swjtu.edu.cn, and Hongyu Jia; hongyu1016@swjtu.edu.cn

Received 3 December 2020; Revised 6 July 2021; Accepted 22 October 2021; Published 7 January 2022

Academic Editor: Marcello Vanali

Copyright (C) 2022 Qihui Peng et al. This is an open access article distributed under the Creative Commons Attribution License, which permits unrestricted use, distribution, and reproduction in any medium, provided the original work is properly cited.

\begin{abstract}
Assessing the seismic performance of the gantry crane is significant since the structure is more vulnerable to earthquakes with the increase in size and lifting weight capacity. This paper aims to investigate the seismic response of the gantry crane incorporating near-field ground motions using incremental dynamic and endurance time analysis (IDA and ETA) methods. To model the structure accurately, a nonlinear finite element model of the gantry crane considering the viscoelastic effect is developed in the OpenSees platform. Then, the IDA method is also carried out for a comparison with the ETA method. The results of the two methods are consistent with a correlation of $93.9 \%$ while the computational demand of the ETA method is much less than those of the IDA method. To study further, both the seismic incident angle and the application of viscous dampers using the Maxwell model are analyzed and discussed in detail. The results show that seismic incident angle has a distinct influence on the maximum seismic displacement and viscous dampers can significantly reduce the seismic demand of the gantry crane. These findings support the seismic design of gantry cranes and evaluate the structural seismic performance efficiently.
\end{abstract}

\section{Introduction}

With the increase of manufacturing and consumption worldwide in the past decades, modern gantry cranes with increasing span and lifting weight have been more commonly designed to elevate large components or structures at the factory, the wharf, or the container freight station. It means the modern gantry cranes are more sensitive to natural hazard, especially earthquake. Many nations, such as China, the United States, and Korea, are economically dependent on logistics transportation through ports and stations, a part of which has been built in the earthquake-prone area. Lockout of the cranes due to earthquakes will cause huge economic losses to the country with rapid economic development. Hence, it is of significant importance to investigate the performance of the modern gantry cranes for guidelines of the future design of the gantry cranes with higher performance, for example, earthquake resistance, small deformation, and strong stability, and so on.

The seismic performance of cranes has long received little attention compared with other large-scale structures such as buildings, bridges, and dams [1-3]. One of the main causes was that the old cranes had relatively small span and lifting capacity compared with modern cranes. Another major cause was the lack of an observing experience of the effects of earthquakes on cranes. However, the 1995 Kobe earthquake has indicated that the impact of the earthquake on the crane structures cannot be omitted and has brought up that the cranes with better seismic-resistant behavior in modern logistics systems count for much. 
Globally, most of the attempts have been made at studying the seismic performance of quay crane such as: Jacobs and Kosbab et al. [4, 5] presented the results of scale testing and analysis of a typical container crane subjected to earthquake loading and Tran et al. [6, 7] used pushover analysis and time-history analysis to study seismic behavior of ship-to-shore container cranes. Some attentions have been paid to the vibration control of the gantry crane. Sagiril [8] developed a five degrees-of-freedom mathematical model of gantry cranes to investigate the dynamic behaviors of cranes under seismic effects. Yazici and Oktay et al. [9-11] studied the active vibration control of container cranes against earthquakes by varied controllers. There are very few studies focused on the structural seismic response of gantry crane: Peng et al. [12] developed the fragility curves of a gantry crane based on the incremental dynamic analysis. Although the low degree-of-freedom mathematical models of the cranes was suitable for studying the vibration control of gantry crane, a detailed finite element (FE) model of the cranes with a high degree of freedom is still requested to generate a crane model whose static and dynamic stiffness are closer to reality.

Based on the above studies, the failure analysis, which is not considered in all the papers mentioned above, is carried out in this study by generating detailed FE models in the OpenSees software to investigate the seismic behavior of a gantry crane. To achieve the purpose, the performance-based earthquake engineering (PBEE) technique is adopted to predict structural behavior and achieve various performance objectives [13]. There are dozens of procedures for the analysis of structures subjected to seismic excitation $[14,15]$, such as pushover analysis (POA) [16], time-history analysis (THA) [17, 18], incremental dynamic analysis (IDA) $[19,20]$, endurance time analysis (ETA) method [21-23], and so on. The ETA method is a dynamic pushover analysis in which the structure is subjected to an intensifying acceleration and its seismic performance can be judged based on the time duration. In this method, only one acceleration is required theoretically to estimate structural dynamic response at different seismic levels from the linear elastic state to nonlinear and collapse states. Therefore, computational efforts can be reduced dramatically during an endurance time analysis, while the accuracy is proved to be consistent with the IDA [24]. The ET method combines the advantages of both the POA method and the IDA method. Hence, it is chosen as the procedure to study the seismic behavior of the gantry crane located in the near-field earthquake-prone area. Besides, the incremental dynamic analysis with 20 near-field seismic waves is also carried out to confirm the accuracy of the ETA method.

To evaluate the structural damage level quantificationally, the definition of damage indexes is the preliminary step. During past decades, different damage indexes, including local and global parameters, have been defined, such as the "Park and Ang" index [25]; "Bozorgnia and Bertero" index [26], taking the structural energy and deformation properties into account; and "Krawinkler and Zohrei" index [27] considering the low-cycle fatigue theory. Thereinto, displacement, and drift ratios are the most widely utilized especially in steel moment-resisting frames (SMRF) are considering their applicability to different analysis procedures and a relatively small amount of calculation [28]. Despite that, the damage indexes, displacement, and drift ratios have not been utilized in the investigation of the seismic behavior of the gantry cranes yet. In the light of the definition of damage indexes in papers $[12,23]$, two new defined damage indexes customized for the gantry cranes are introduced in this research to quantitatively analyze the structural failure mechanism of the gantry crane under seismic waves.

According to the above states, attempts on the seismic performance of the considered gantry crane subjected to near-field ground motions are stated, and the ETA method is used for the first time in seismic assessment of the gantry crane. In the current study, the concept and generation of ET acceleration functions are introduced in Section 2. The FE models of a typical gantry crane are developed in the OpenSees software, and specific demand measures for the gantry crane are defined in Section 3; Then in Section 4, 20 near-field seismic waves are chosen based on the template spectrum response, which is used in the IDA procedure. There are three major issues discussed in Section 5, the results obtained in ET procedure are compared with that in the IDA procedure to discuss the accuracy of ETA method on gantry crane. Then, the seismic incident angle and feasibility of the shock absorption strategy are discussed. Finally, the conclusions are drawn as references for the future design of gantry cranes.

\section{Endurance Time Acceleration Functions}

In the ETA method, a set of predesigned intensifying excitation called endurance time acceleration functions (ETAFs) are generated to evaluate the seismic performance of structures, which is recorded through a time-history analysis procedure. Because of the time-history characteristics of the ETAFs, the state of an investigated structure changes from the elastic phase up to the nonlinear and collapse phases gradually. In performance-based earthquake engineering (PBEE), structures are subjected to different ground motions with intensifying seismic hazard levels [21]. Therefore, the ETA analysis can meet the requirement naturally since each specific time can be correlated to a specific intense measure (IM).

To generate the ETAFs, a design spectrum should be firstly defined based on the Chinese Seismic Code [29]. Then, an artificial time-history seismic wave is generated according to the design spectrum. Next, the initial seismic wave is brought into the optimization procedure to make the response spectrum of the seismic wave closer to the design spectrum. Finally, after enough iterations, the modified ETAFs will be obtained with acceptable accuracy.

Evidently, a major issue in predicting the structural seismic performance precisely depends on the generation of usable ETAFs. To solve the problem, the optimization strategy is that the response spectrum of the ETAFs linearly intensifies with time and remains compatible with a prespecified design spectrum curve as far as possible [22]. The 
relationships between the response spectrum of the acceleration and displacement function $\left(S_{a}(T, t), S_{u}(T, t)\right)$ and prespecified design spectrum $\left(S_{a T}(T)\right)$ can be explained as follows:

$$
\begin{gathered}
S_{a T}(T, t)=\frac{t}{t_{\text {Target }}} S_{a T}(T), \\
S_{u T}(T, t)=\frac{t}{t_{\text {Target }}} S_{a T}(T) \frac{T^{2}}{4 \pi^{2}},
\end{gathered}
$$

where $t_{\text {Target }}$ means a scale factor. In this paper, $t_{\text {Target }}=10 \mathrm{~s}$. It means when $t=10 \mathrm{~s}$, the scale factor is 1.0 [30].

The main purpose of the optimization procedure is to generate the acceleration function $a_{g}(t)$ so that $S_{a}(T, t)$ is as close as possible to $S_{a T}(T, t)$, which can be explained as follows:

$$
\text { Minimize } F\left(a_{g}\right)=\int_{0}^{T_{\max }} \int_{0}^{t_{\max }}\left\{\left[S_{a}(T, t)-S_{a T}(T, t)\right]^{2}+\alpha\left[S_{u}(T, t)-S_{u T}(T, t)\right]^{2}\right\} \mathrm{d} t \mathrm{~d} T
$$

where $F\left(a_{g}\right)$ is the optimization target function and $\alpha$ is a relative weight parameter that can be used to adjust the effective penalty [22]. In this study, $\alpha=1.0$ is chosen to consider the influence of the acceleration and displacement response spectra with the same weight coefficient simultaneously.

The optimization procedure can be performed after generating acceleration in line with the target response spectrum. The generation of ETAF can be described in three steps as follows: (1) generating the artificial seismic wave based on the design response spectrum, (2) optimizing the seismic wave by comparing the response spectrum of the seismic wave with the design response spectrum, and (3) iterating 50 times and obtaining the modified ETAF. Figures 1 and 2 show the initial artificial seismic wave and the modified ETAF (ETA50g02) after the optimization procedure. It should be noted that only the ascent stage of the artificial wave is considered to reduce the calculating amount during the procedure, which will not affect the accuracy of the modified ETAF. Figure 3 depicts the response spectra of the ETA50g02 at different time intervals. As can be seen, if an interval of $t=0-20 \mathrm{~s}$ is considered, its response spectrum is almost twice as much as that for the same ETAF for a window of $t=0-10 \mathrm{~s}$. In the same manner, the response spectrum of $t=0-30 \mathrm{~s}$ is three times more than that of $t=0-10 \mathrm{~s}$. In other words, the response spectrum is expected to increase linearly by the time. Besides, the response spectra of ETA50g02 fit the template response spectra well. This means the accuracy of ETA50g02 is within a reasonable range.

In order to draw a more reliable conclusion at the end of the paper, three different ETAFs (ETA70g01-03) are generated and utilized to obtain the dynamic response of the gantry crane, whose eigen periods are $0.45 \mathrm{~s}, 0.5 \mathrm{~s}$, and $0.55 \mathrm{~s}$, respectively. As will be explained later, the average procedure considering three different ETAFs can reduce the effect of randomness greatly compared with the situation that only one ETAF is considered.

\section{Design of Gantry Cranes}

3.1. Finite Element Model. In this paper, a typical gantry crane located in the near-field earthquake-prone area is chosen as the research object shown in Figure 4. The gantry crane mainly contains a pair of sill beams, support beams, flexible legs, rigid legs, and trolley girders, all of which are constructed by Q235 steel. Moreover, it has a total height of $15 \mathrm{~m}$ (including the height of cartwheels of the crane structure), and the span between flexible legs and rigid legs is $35 \mathrm{~m}$. In terms of size, the rigid leg is larger than the flexible leg. Flexible legs are two-force rods with smaller crosssections compared with rigid legs. They are utilized to reduce the lateral force from the trolley.

Based on the above information, the finite element (FE) model of the gantry crane is established in the OpenSees software, which is used to analyze advanced structural and geotechnical systems [31]. The schematic 3D model of the gantry crane is shown in Figure 4(a). The black points in this model play an important role in the definition of variable section parameters of beams and columns as reference points. Since the section parameters of the columns vary with length, the gap between two reference points on columns is relatively small to construct the columns more accurately. Since the section parameters of the columns vary with length, the gap between two reference points on columns is relatively small to construct the columns more accurately. The length of segments between reference points is the distance between diaphragm plates inside the box girders. The black lines between two points are the nonlinear columns and beams used to simulate the structure of the gantry crane. Moreover, a centerline approximation is applied, and the effect of the panel zone is neglected since the extra flexibility introduced to the system due to centerline dimensions counteract the influence of omission of panel zone [32]. Besides, the second-order effect ( $P-\Delta$ effect) is considered in this case to take geometric nonlinearity into account, the influence of which is too remarkable to ignore since the nonlinear deformation or permanent deformation of the structure will increase dramatically [33]. Furthermore, the elastic modulus, mass density, yield stress of Q235 steel, and the damping ratio are, respectively, equal to $2.01 \times 10^{11}$ $\mathrm{Pa}, 7,800 \mathrm{~kg} / \mathrm{m}^{3}, 235 \mathrm{MPa}$, and $3 \%$. At the bottom of the legs, three displacements and $Y$ and $X$ rotation (along vertical and gantry travel direction) degree of freedoms are restricted. It is worth noting that the trolley travel direction, vertical 


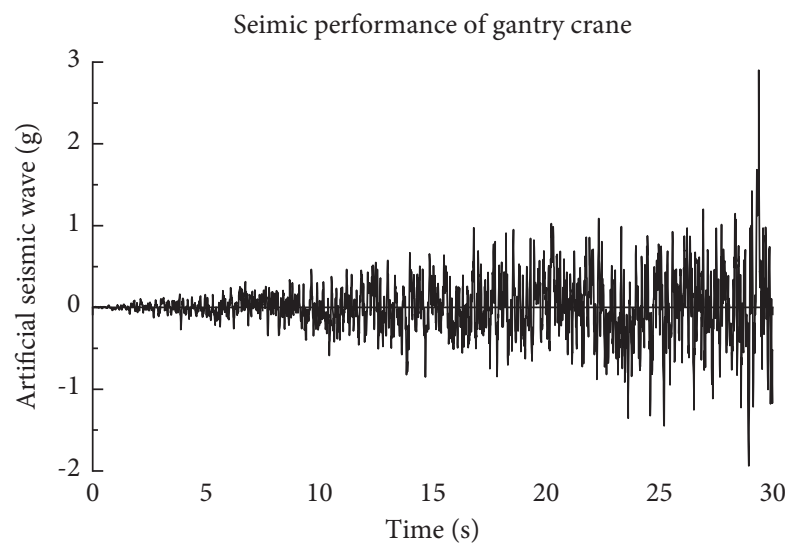

Figure 1: Artificial seismic wave.

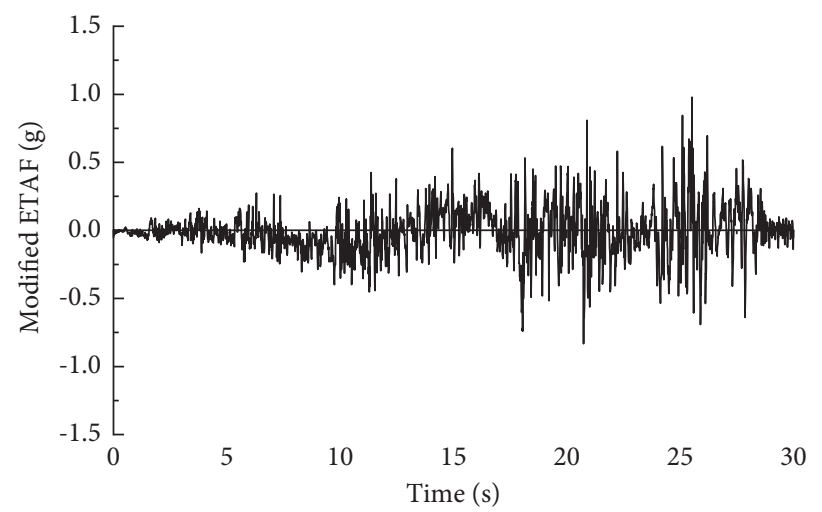

Figure 2: ETA50g02.

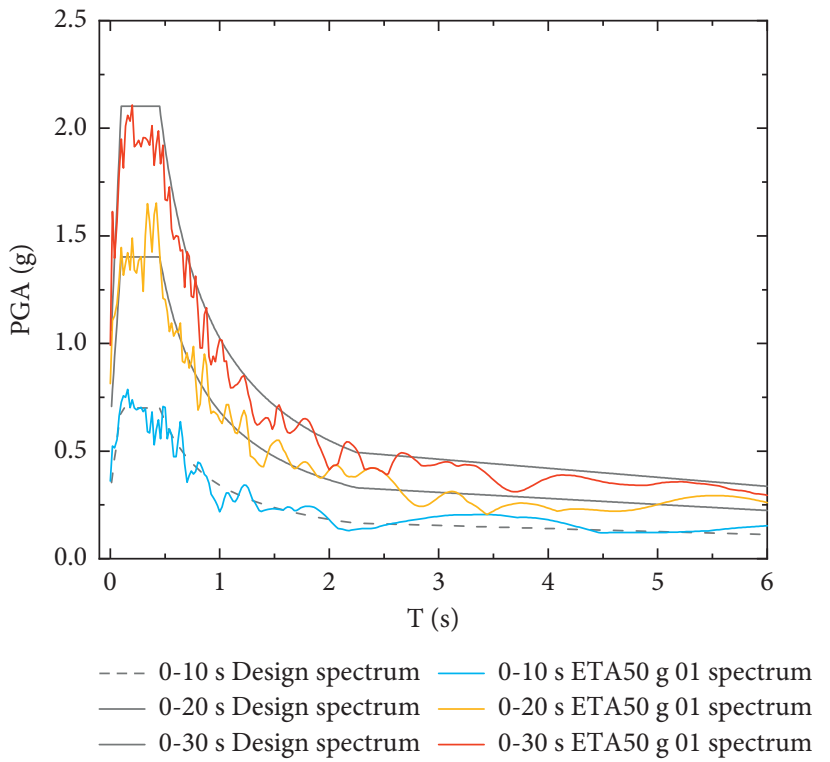

(a)

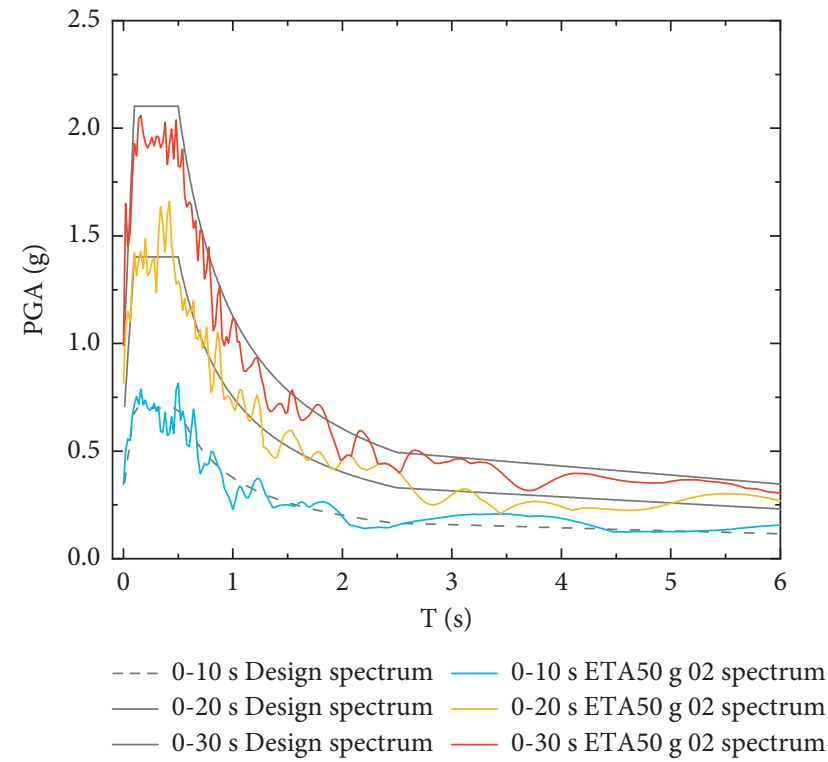

(b)

Figure 3: Continued. 


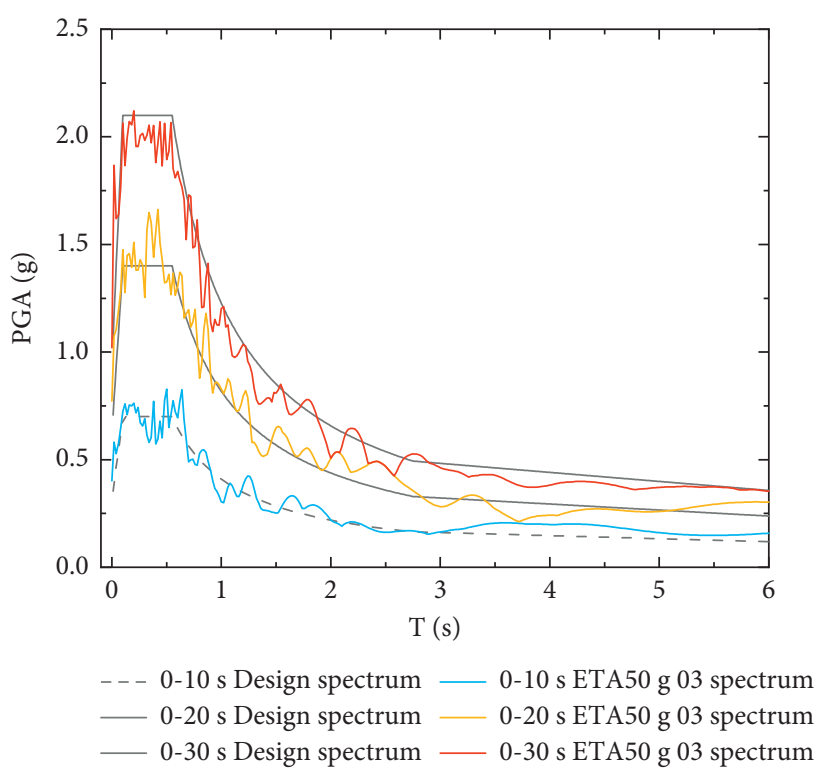

(c)

FIgURE 3: Spectra of ET acceleration functions.

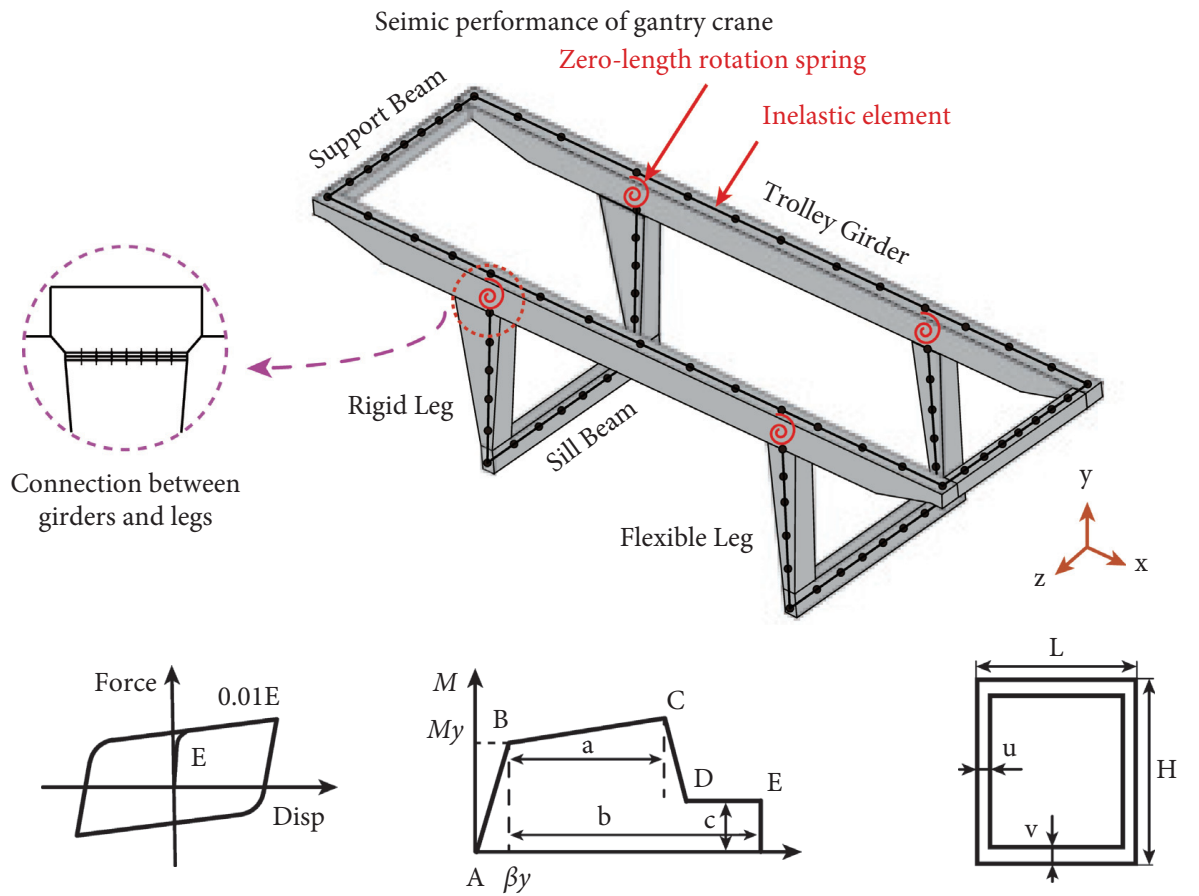

Figure 4: Model of gantry crane.

direction, and gantry travel direction are correspondingly described as $X, Y$, and $Z$ coordinates separately.

To define the nonlinear behavior of the gantry crane more precisely, the junctions where trolley beams and columns are connected are modeled as rotational springs defined by zerolength element and hysteretic material in OpenSees. Considering the beam itself as a complete whole, only one spring at the junction is developed to generate a more realistic model. A schematic of the spring model and the constitutive model of the spring is shown in Figure 4.
Different from the objects of previous studies [34, 35], in which the columns and beams are considered elastic, the span of the gantry crane is too long to ignore its nonlinear behavior during an earthquake. Therefore, all the beams and columns are considered as nonlinear elements (see Figure 4), which are simulated by dispBeamColumn elements in OpenSees software.

According to FEMA 365, the moment versus rotation curve model is established in Figure 4. The values of $a, b$, and $c$ are determined by the material and section properties of 
the gantry crane. As shown in Figure 4, Giuffré-Menegotto-Pinto model with isotropic strain hardening is used as the model of steel material. The slope $E$ means the elasticity modulus of the steel and equals to $2.01 * 10^{11} \mathrm{~Pa}$. The slope $0.01 \mathrm{E}$ equals to $1 \%$ of $E$. Table 1 shows the section properties of girders and legs. They are used to determine the values of $\mathrm{a}, b$, and $c$. According to FEMA 365 [36], $a=4 \beta_{y}, b=6 \beta_{y}$, and $c=0.2 M_{y}$ in this case, respectively.

3.2. Maxwell Model. Under the action of earthquakes, the legs of the gantry crane will sway substantially and even be damaged under seismic excitation. In order to improve the gantry crane's seismic capacity, an inclined bracing viscous damper called the Maxwell model is utilized for the first time to reduce the deformation of the structure.

As can be seen in Figure 5, four dampers are used. They are mounted between the middle points of girders and the endpoints of legs. This erection scheme will not influence the normal assembly and operation of the gantry crane.

Maxwell model can be represented by a purely viscous damper and a purely elastic spring connected in series. In this configuration, under applied axial stress, the total stress, $\sigma_{\text {Total }}$, and the total strain, $\mathcal{E}_{\text {Total }}$, can be defined as follows:

$$
\varepsilon_{\text {Total }}=\varepsilon_{D}+\varepsilon_{S}
$$

where the subscript $D$ indicates the stress-strain in the damper and the subscript $S$ indicates the stress-strain in the spring.

Taking the derivative of strain with respect to time, we obtain

$$
\begin{aligned}
\frac{\mathrm{d} \varepsilon_{\text {Total }}}{\mathrm{d} t} & =\frac{\mathrm{d} \varepsilon_{D}}{\mathrm{~d} t}+\frac{\mathrm{d} \varepsilon_{S}}{\mathrm{~d} t} \\
& =\frac{\sigma}{\eta}+\frac{1}{E} \frac{\mathrm{d} \sigma}{\mathrm{d} t}
\end{aligned}
$$

where $E$ is the elastic modulus and $\eta$ is the material coefficient of viscosity. This model describes the damper as a Newtonian fluid and models the spring with Hooke's law.

3.3. Selection of Ground Motions. Since the gantry crane is located in a near-field earthquake-prone area in China, 20 near-field ground motions are chosen from the Pacific Earthquake Engineering Research Center (PEER) NGA database based on the Chinese design response spectrum whose closest distance to rupture plane are all less than $20 \mathrm{~km}$. They are all listed in Table 2 Figure 6 plots the mean spectrum and acceleration spectra of these seismic records. The mean spectrum coincides with the design response spectrum in an acceptable error range.

\section{Analysis of Results}

4.1. Comparative Study. In the ET method, it is essential to perform a calibration. In this circumstance, each ETAF has been multiplied by a factor of 4 in order to be strong enough
TABLE 1: Section properties of the gantry crane.

\begin{tabular}{lccc}
\hline Parameters & Trolley girder & Flexible leg & Rigid leg \\
\hline$b_{f}(\mathrm{~mm})$ & 1,535 & 1,333 & 3,000 \\
$t_{f}(\mathrm{~mm})$ & 14 & 8 & 10 \\
$F_{y}(\mathrm{Mpa})$ & 235 & 235 & 235 \\
$h(\mathrm{~mm})$ & 1,987 & 1,258 & 1,500 \\
$t_{w}(\mathrm{~mm})$ & 10 & 10 & 10 \\
\hline
\end{tabular}

Note: $b_{f}$ : width of the flange slab; $t_{f}$ : thickness of the flange slab; $F_{y}$ : yield stress of the steel; $h$ : distance between the two flange slabs; and $t_{w}$ : thickness of the web slab.

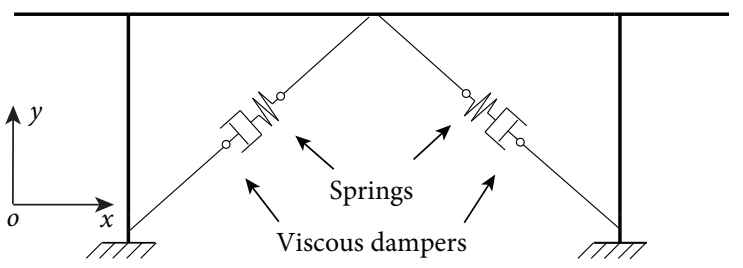

Figure 5: Maxwell model of damper equipped gantry crane.

to cause collapse. As will be explained later, a factor of 2 is also utilized to generate better cubic fitting curves. In the ET analysis, a structural response such as midspan displacement, reaction force, drift ratio, and so on is plotted over time.

To quantificationally evaluate the seismic response of the gantry crane, a damage measure called local displacement ratio (LDR) is utilized [12], the definition of which is shown as follows:

$$
\mathrm{LDR}=\left\{\begin{array}{l}
\frac{\Delta x}{h}, \\
\frac{\Delta y_{g}}{L_{g}}, \\
\frac{\Delta y_{c}}{L_{c}},
\end{array}\right.
$$

where $\Delta x=$ displacement of the joint of the leg and the girder in the $X$ direction; $h=$ height of the leg; $\Delta y_{g}=$ displacement of the girder in the $Y$-direction; $L_{g}=$ length of the girder; $\Delta y_{c}=$ displacement at the valid cantilever end in the $Y$-direction; and $L_{c}=$ length of the valid cantilever.

Figure 7 shows the time histories of lateral displacement of the gantry crane under ETA50g01. Based on the data, the maximum absolute value of the response is plotted versus time and known as the ET curve. The design formula is as follows:

$$
f(t)^{\mathrm{EDP}}=\max (\operatorname{Abs}(f(\tau), \tau \in[0, t])),
$$

where $f(t)^{\mathrm{EDP}}$ means the engineering demand parameter (EDP) at time $t$ and $f(\tau)$ represents the structural response from $\tau=0 s$ to $\tau=t s$.

In most situations, the shape of ET curves is serrated and is inconvenient to utilize. To solve the problem, some fitting methods have been proposed [37] such as the moving 
TABLE 2: Summary of selected near-field records.

\begin{tabular}{lccccc}
\hline \multirow{2}{*}{ ID No. } & \multicolumn{2}{c}{ Earthquake } & & \multirow{2}{*}{ PGA $(\mathrm{g})$} & Recording station \\
\hline 1 & Name & Year & Magnitude, M & & \multicolumn{1}{c}{$R_{\text {rup }}(\mathrm{km})$} \\
2 & Imperial Valley-02 & 1940 & 6.95 & 0.2807955 & El Centro array \#9 \\
3 & Irpinia_Italy-01 & 1980 & 6.9 & 0.129652 & Bagnoli Irpinio \\
4 & Corinth_Greece & 1981 & 6.6 & 0.236771 & Corinth \\
5 & Loma Prieta & 1989 & 6.93 & 0.2852704 & Gilroy - historic bldg. \\
6 & Cape Mendocino & 1992 & 7.01 & 0.1167631 & Fortuna - Fortuna blvd. \\
7 & Landers & 1992 & 7.28 & 0.2735839 & Joshua Tree \\
8 & Northridge-01 & 1994 & 6.69 & 0.3450987 & Arleta - Nordhoff Fire Sta \\
9 & Kobe_Japan & 1995 & 6.9 & 0.1845571 & Fukushima \\
10 & Kocaeli_Turkey & 1999 & 7.51 & 0.2100834 & Arcelik \\
11 & Chi-Chi_Taiwan & 1999 & 7.62 & 0.1742769 & CHY010 \\
12 & Duzce_Turkey & 1999 & 7.14 & 0.107237 & Lamont 1058 \\
13 & Hector Mine & 1999 & 7.13 & 0.2654663 & Hector \\
14 & Cape Mendocino & 1992 & 7.01 & 0.1773806 & Bunker Hill FAA \\
15 & Tottori_Japan & 2000 & 6.61 & 0.25177 & SMN001 \\
16 & Montenegro_Yugoslavia & 1979 & 7.1 & 0.1832788 & Ulcinj - Hotel Albatros \\
17 & Chuetsu-oki_Japan & 2007 & 6.8 & 0.1881915 & Joetsu Ogataku \\
18 & Iwate_Japan & 2008 & 6.9 & 0.2886351 & IWT010 \\
19 & El Mayor-Cucapah_Mexico & 2010 & 7.2 & 0.2484907 & 19.96 \\
20 & Darfield_New Zealand & 2010 & 7 & 0.1857917 & Canterbury Aero Club \\
\hline
\end{tabular}

Note: $R_{\text {rup }}$ means the closest distance to rupture the plane.

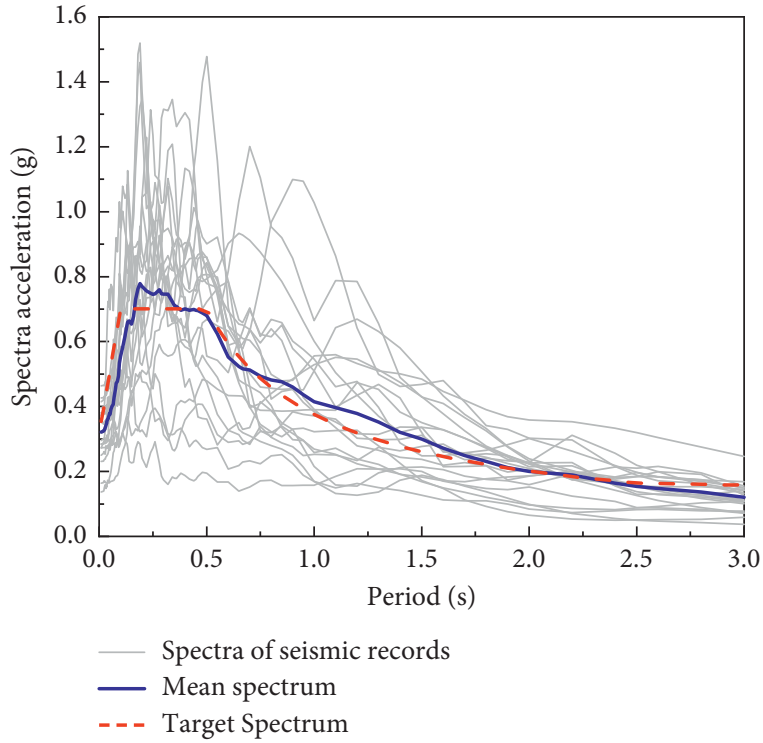

Figure 6: Spectra of seismic records [12].

average method, the polynomial fitting method, the combination of linear and polynomial fitting method, and so on. Given the accuracy and convenience of the results, the trinomial fitting technique is utilized in this research whose precision will be proved accurate enough in the performance prediction of the gantry crane. Figure 8 shows the smoothed ET curves for the sample gantry crane. The acceleration with a factor of 2 is also introduced because of the distortion of the fitting curve with a factor of 4 at the beginning. Compared with the combination of linear and polynomial fitting method, the currently used approach does not need to judge

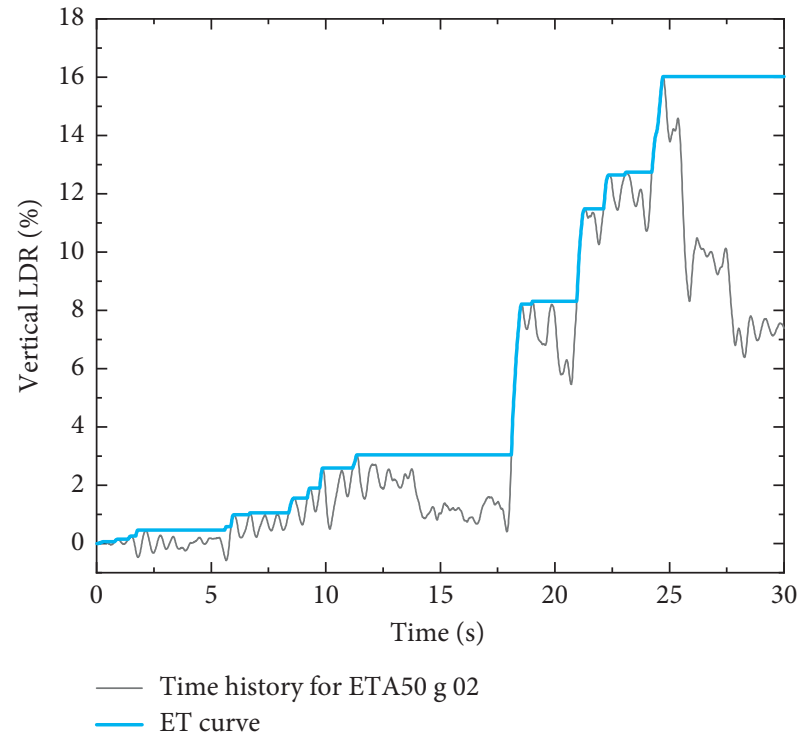

Figure 7: Generation of ET curve.

the nonlinear state of the gantry crane artificially and is proved to be accurate enough in this paper.

In this research, three limit states are adopted for the gantry crane according to [], and they are serviceability (SA), damage control (DC), and collapse prevention (CP), correspondingly. And the thresholds of the maximum LDR in $X$ direction are $0.368 \%, 0.958 \%$, and $3.442 \%$, respectively. Table 3 shows the equivalent PGA and time at different limit states with different eigen periods according to Figure 3. It should be noted that the equivalent time means the ET curve with a factor of 2 . If the equivalent time is less than $5.1 \mathrm{~s}$, the 


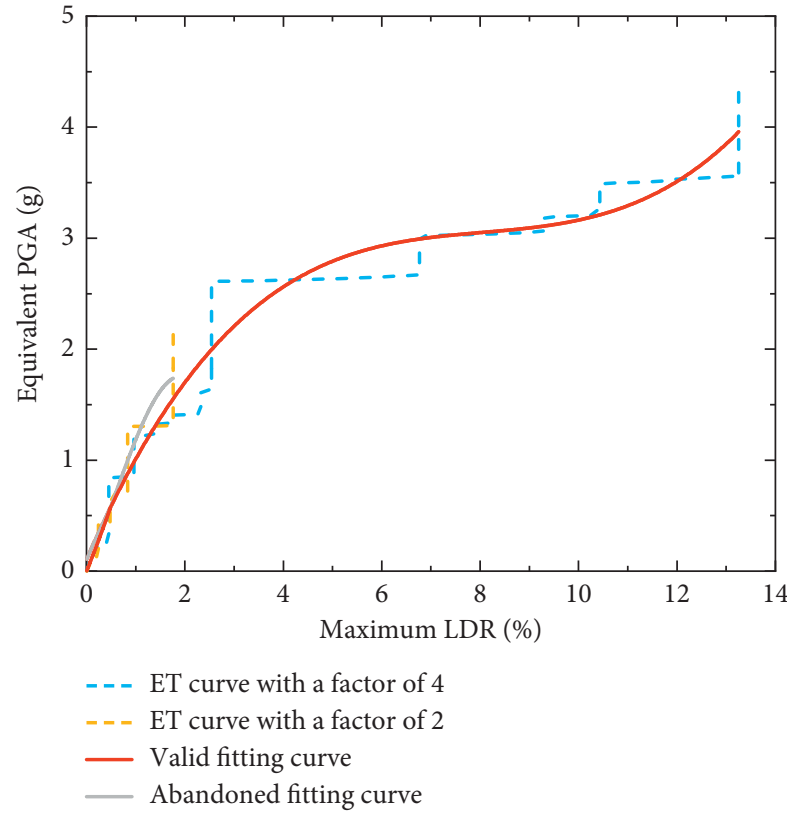

(a)

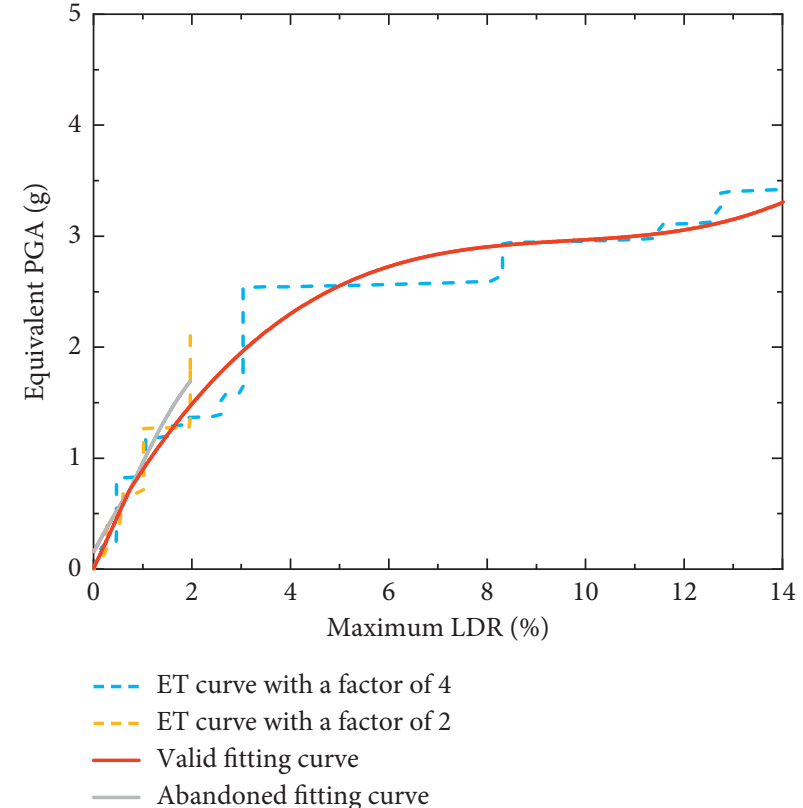

(b)

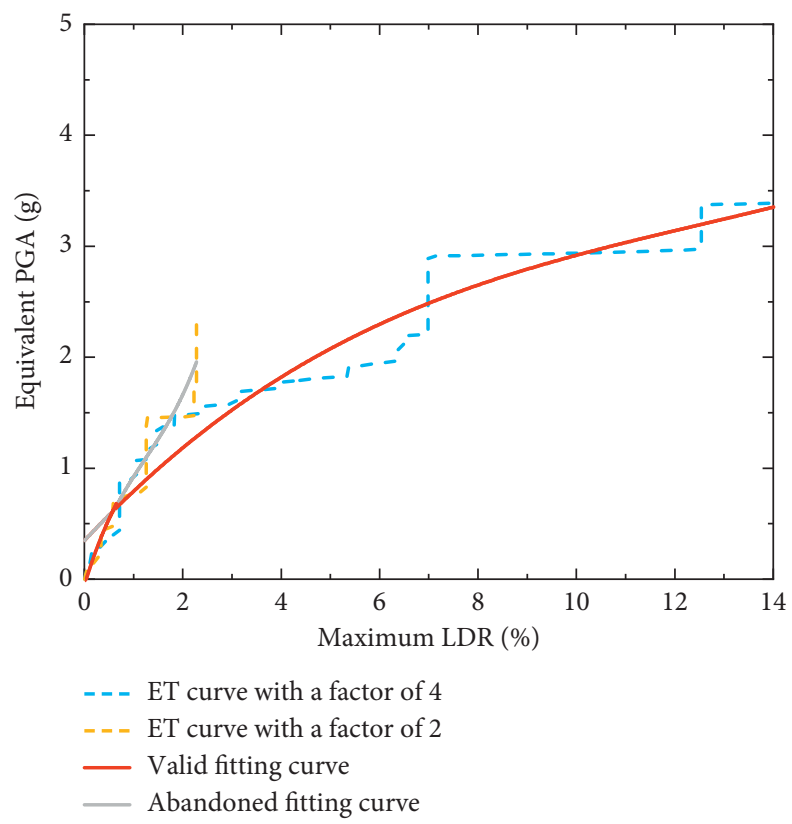

(c)

Figure 8: Generation of fitting ET curves.

TABle 3: Equivalent PGA and time at different limit state.

\begin{tabular}{lcccccc}
\hline \multirow{2}{*}{$\mathrm{T}(\mathrm{s})$} & \multicolumn{3}{c}{ Equivalent PGA $(\mathrm{g})$} & \multicolumn{3}{c}{ Equivalent time $(\mathrm{s})$} \\
& SA & DC & CP & SA & DC & CP \\
\hline 0.45 & 0.39 & 0.94 & 2.32 & 4.90 & 11.81 & 29.16 \\
0.50 & 0.35 & 0.87 & 2.09 & 4.95 & 12.30 & 29.55 \\
0.55 & 0.42 & 0.76 & 1.64 & 5.45 & 9.85 & 21.26 \\
Average & 0.39 & 0.94 & 2.32 & 5.10 & 11.32 & 26.66 \\
\hline
\end{tabular}

structure sustained no damage under the ground motion. When the equivalent time is between $5.1 \mathrm{~s}$ and $11.32 \mathrm{~s}$, the structure is in the SA state. Similarly, the structure is in the
DC state when the equivalent time is between $11.32 \mathrm{~s}$ and $26.66 \mathrm{~s}$. And the structure is in the CP state when the time is more than $26.66 \mathrm{~s}$.

To compare the ET analysis with that of the IDA analysis, the ET curves are plotted in PGA versus EDP axes as is the practice in plotting IDA results. This can be easily done using (8). In Figure 9, the average ET curve and the average IDA curve are shown for the response of the gantry crane. The local displacement ratio is used as EDP. Generally, the ET curve and the IDA curves have a good consistency for the gantry crane in different ranges of response. 


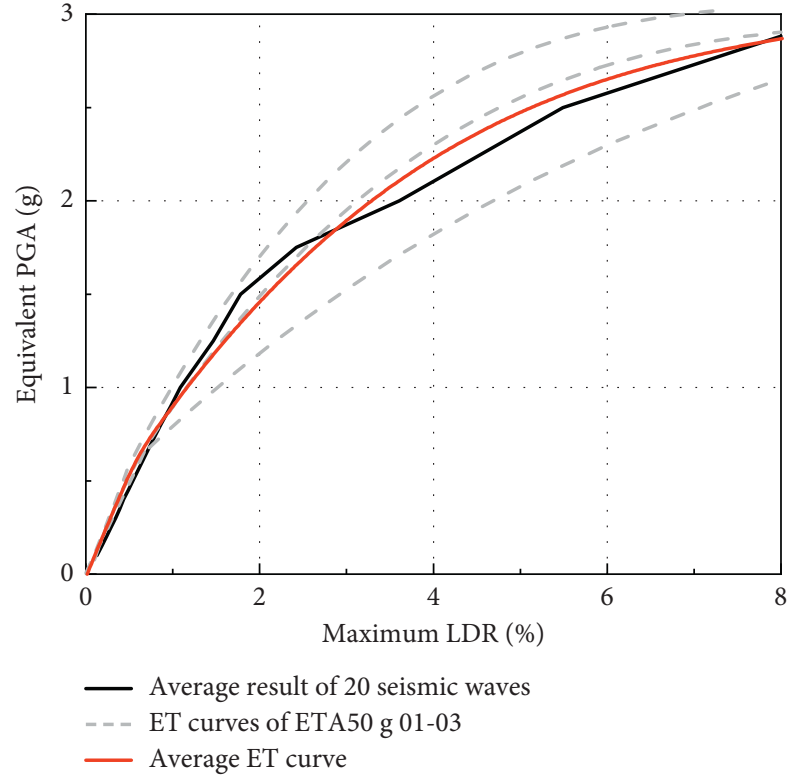

Figure 9: Comparison of ET and IDA curves.

$$
\text { PGA }=\frac{\text { PGA }_{\text {target }}}{t_{\text {target }}} t_{\mathrm{ET}},
$$

where PGA $\mathrm{A}_{\text {target }}$ means the maximum PGA when $t \leqslant t_{\text {target }}$ and $t_{\mathrm{ET}}$ means the endurance time.

As illustrated in Figure 9, the average ET result correlates satisfactorily with the IDA result. However, further study should be carried out to compare the ET and the IDA results quantitatively. Figures 10 and 11 show the correlation between damage indexes calculated from the IDA and the ET method under the ETA50 g series. In Figure 10, the data of the IDA results is the same as that in Figure 11, but the ET results are the averages of three accelerations (ETA50 g series). The near-unity coefficients of determination ( $R^{2}$ values) are equal to 0.97 and 0.99 , respectively. And that shows a fine correlation between the results, while the average procedure improves the correlation further. Besides, the linear relations with the coefficient are 0.85 and 0.94 separately. The results indicate that the seismic demand calculated by the ETA method is bigger than that calculated by the IDA method. Moreover, the average result of three accelerations is closer to the IDA result than that of one acceleration. Three nonlinear analyses are executed in the ETA method, while more than 400 nonlinear analyses have been carried out in the IDA method to reduce the effect of earthquake randomness. Given that, a conclusion can be easily drawn that the amount of computation can be reduced greatly by using the ETA method with acceptable accuracy.

4.2. Influence of Seismic Incident Angles. In the above analysis, the ETAFs are only input along the trolley travel direction (i.e., $X$ direction) of the gantry crane. This is because the girders are strong enough to resist collapse in a vertical direction theoretically and practically. Therefore, the

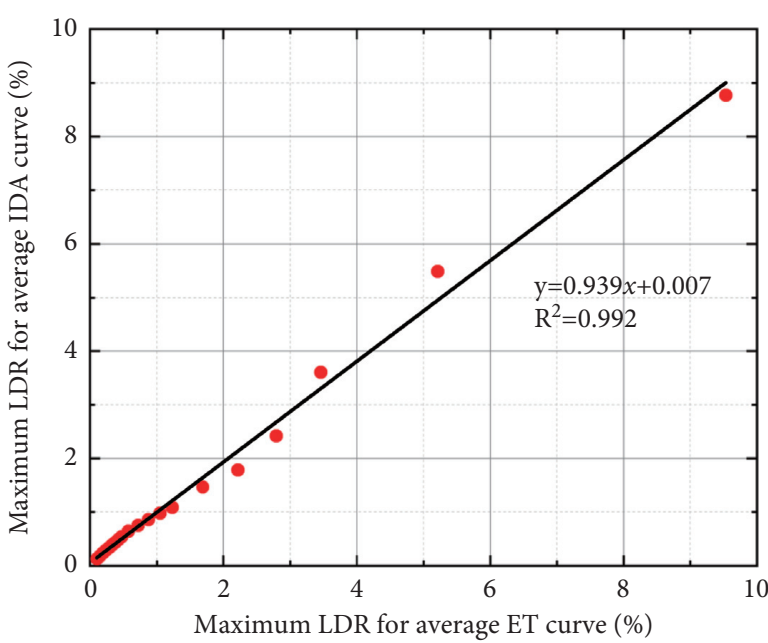

FIGURE 10: Correlation between ET and IDA methods.

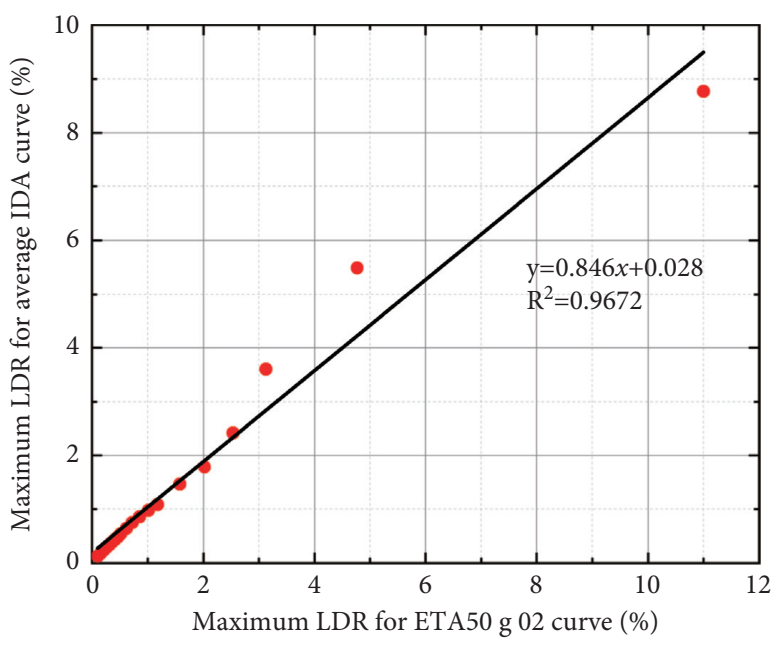

FIgURE 11: Correlation between ET and IDA methods.

influence of the vertical component of the ground motion is ignored in this section.

However, the seismic excitation is not always perfectly aligned with the trolley travel direction. Given that, it is quite necessary to investigate the influence of seismic incident angles on the dynamic response of the gantry crane. Figure 12 shows the schematic diagram of the seismic incident angle. As can be seen, the whole structure of the gantry crane rotates to simulate the change of seismic incident angle, while the direction of seismic excitation remains unchanged. This strategy is easy to implement in the OpenSees software, and there is no need to calculate the components of the seismic excitation along with the $X$ and $Y$ directions.

It should be noted that the angle increases from $0^{\circ}$ to $180^{\circ}$, with an increment of $15^{\circ}$. Figures 13 and 14 show the various lateral and vertical LDR with the incident angle comparatively. As shown in the former graph, when $t=10 \mathrm{~s}$, the incident angle of $105^{\circ}$ is the most critical direction, while $150^{\circ}$ is the most favorable direction of the gantry crane. It is worth noting that the lateral leg deformations achieve 


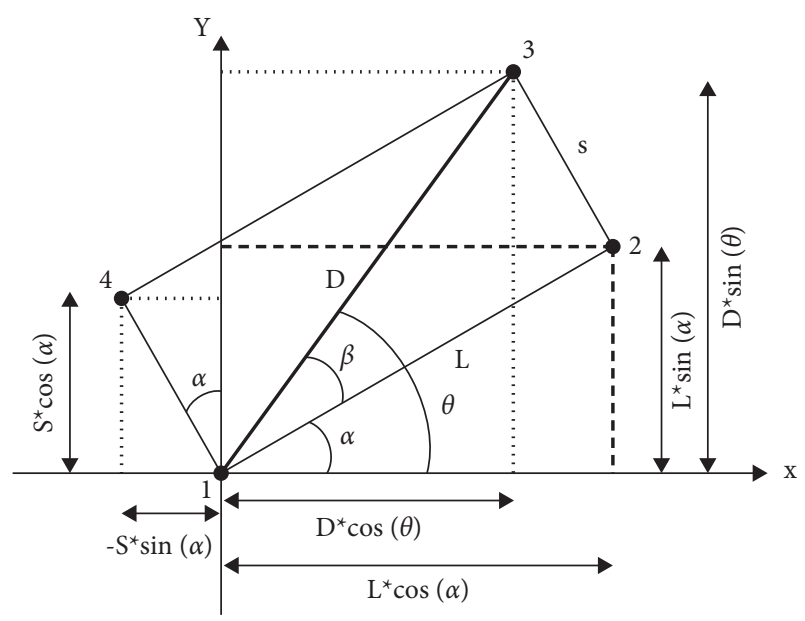

FIGURE 12: Schematic diagram of altering seismic incident angle.

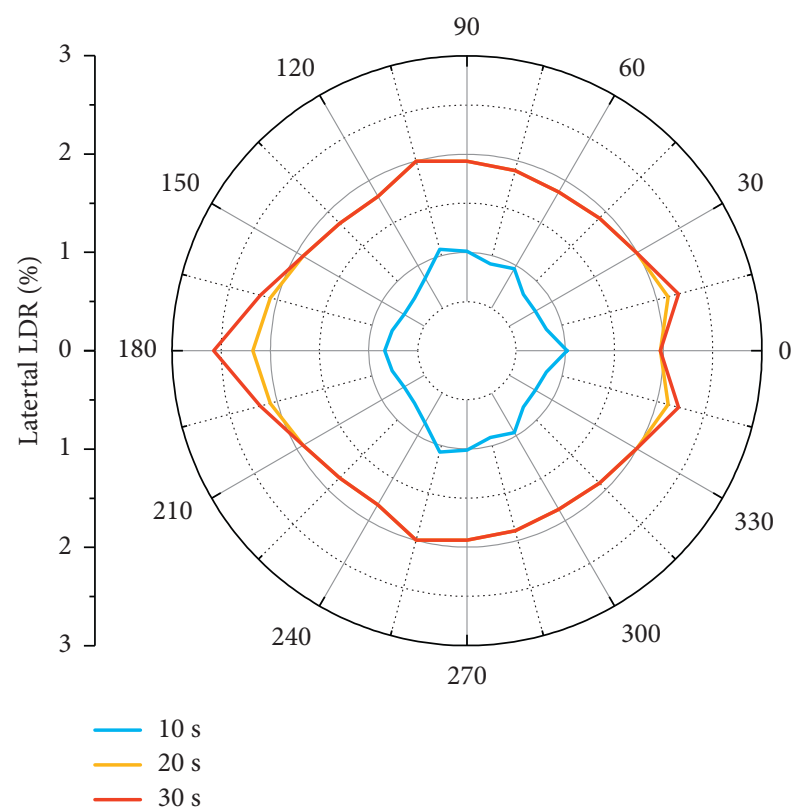

Figure 13: Maximum lateral LDR for different angles.

maximal values at the incident angle of $0^{\circ}$ and $180^{\circ}$. Meanwhile, the deformation at $0^{\circ}$ is larger than that at $180^{\circ}$ when $t=10 \mathrm{~s}$. However, the conclusion is the opposite when it comes to $t=20 \mathrm{~s}$ and $30 \mathrm{~s}$. In that case, the deformation at 180 is larger than that at $0^{\circ}$. And the incident angle of $180^{\circ}$ is the most critical direction of the gantry crane. This is because when the seismic excitation is relatively small and reaches the flexible legs first (i.e., incident angle of $0^{\circ}$ ), the flexible legs will dissipate some part of the earthquake energy to keep the structure linear. However, if the rigid legs are reached first, the legs will absorb the energy and perform less structural deformation. With the increasing of ground motion, the rigid legs will be into a plastic state rapidly and lead to major deformation of the gantry crane if the rigid legs are reached first. This can explain the phenomenon described above.

As illustrated in Figure 14, the incident angle of $0^{\circ}$ is the most critical direction, while the $180^{\circ}$ is the most favorable

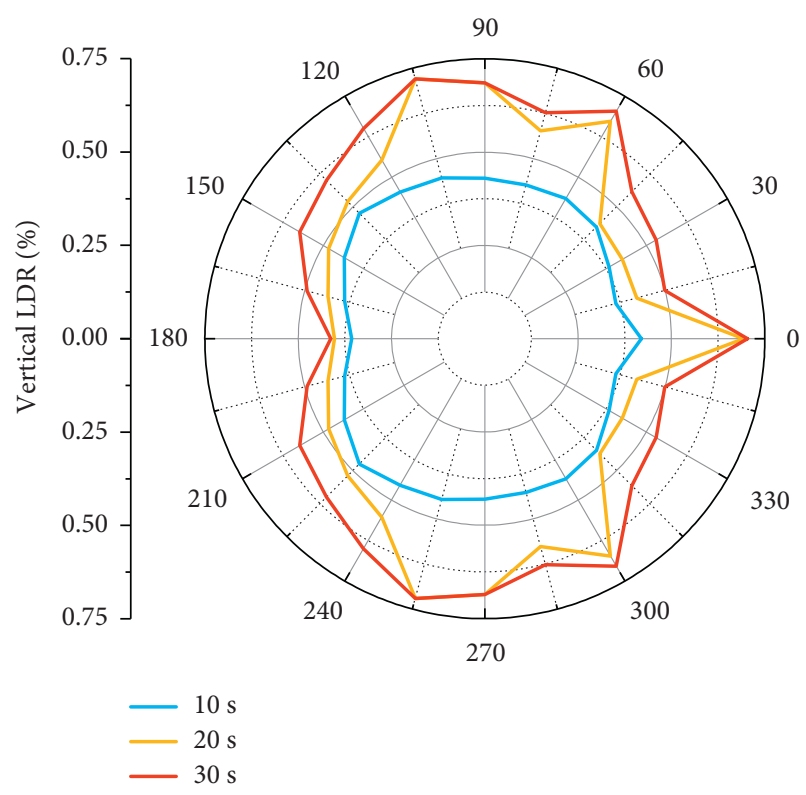

FIGURE 14: Maximum vertical LDR for different angles.

direction of the gantry crane. When $t=20 \mathrm{~s}$ and $30 \mathrm{~s}$, the vertical displacements achieve maximal values at the incident angle of $60^{\circ}$ and $105^{\circ}$.

Above all, the structure responses are different when the seismic incident angles are changed. Table 4 shows the difference between the maximum and minimum values $(\gamma, \beta)$. The parameter, per centum $(\theta)$, evaluates the effect of the seismic incident angle on the response of the gantry crane quantificationally. The influence of the seismic incident angle is between $20.3 \%$ and $78.9 \%$.

4.3. Effect of Damping Devices. In this section, the property of the damping device has been investigated to absorb the shock induced by earthquakes. The theory of damping device is illustrated in Section 3, which can be easily executed in the OpenSees platform by viscous damper element. The viscous damper is modeled with a Two Node Link element. An idealized schematic of the model is presented in Figure 4.

Considering the effect of the viscous damper on the structural response, from 35 to $85 \mathrm{kN} / \mathrm{mm}$ is the range of structure stiffness coefficient. And the damping coefficient of the viscous damper ranges from 0 to $20 \mathrm{kNs} / \mathrm{mm}$. The ET acceleration function ETA50g02 is chosen as the ground motion to study the lateral leg deformation considering viscous damper influence.

Figure 15 shows the leg deformation of the gantry crane when the duration time $t=10 \mathrm{~s}, 20 \mathrm{~s}$, and $30 \mathrm{~s}$, respectively, and the seismic excitation is in the $X$ direction. As can be seen in Figure 15(a), the leg deformation decreases with the increase of $C_{D}$, and the trend is obvious when $C_{D}<5 \mathrm{Ns} / \mathrm{m}$. Besides, the impact of the structure stiffness coefficient is relatively small on the response of lateral leg deformation. The phenomenon attributes to the fact that the ground motion is comparatively small in the first 10 seconds. In Figure 15(b), the regularity of the damping coefficient influence is similar to 
TABLe 4: The difference between maximum and minimum values at three typical times.

\begin{tabular}{|c|c|c|c|c|c|c|}
\hline \multirow{2}{*}{ Time (s) } & \multicolumn{3}{|c|}{ Lateral LDR } & \multicolumn{3}{|c|}{ Vertical LDR } \\
\hline & 10 & 20 & 30 & 10 & 20 & 30 \\
\hline$\gamma(\%)$ & 1.07 & 2.18 & 2.58 & 0.20 & 0.31 & 0.31 \\
\hline$\beta(\%)$ & 0.74 & 1.81 & 1.81 & 0.15 & 0.17 & 0.18 \\
\hline$\theta(\%)$ & 44.8 & 20.3 & 42.4 & 33.1 & 78.9 & 74.8 \\
\hline
\end{tabular}

Note: $\theta=(\gamma-\beta) / \beta$.

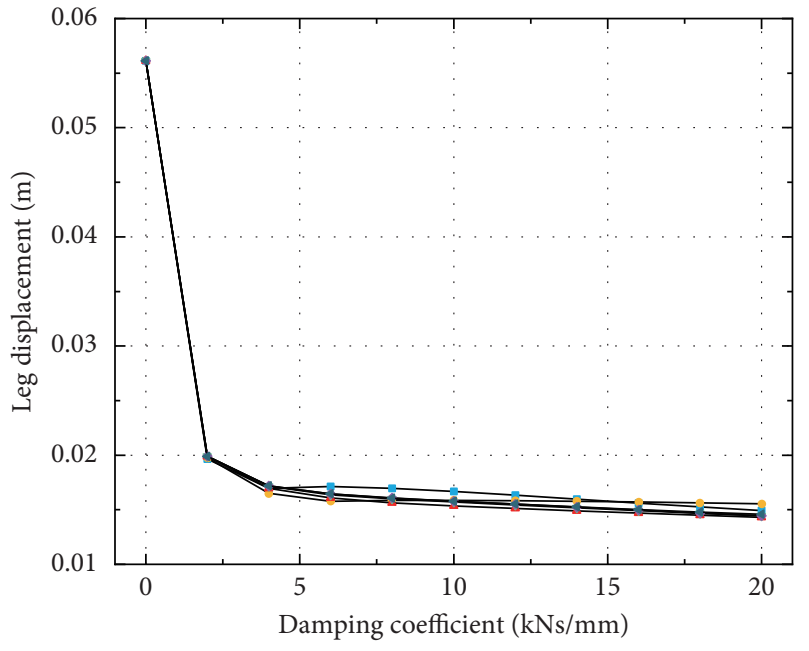

Struct stiffness coefficient $(\mathrm{kN} / \mathrm{mm})$

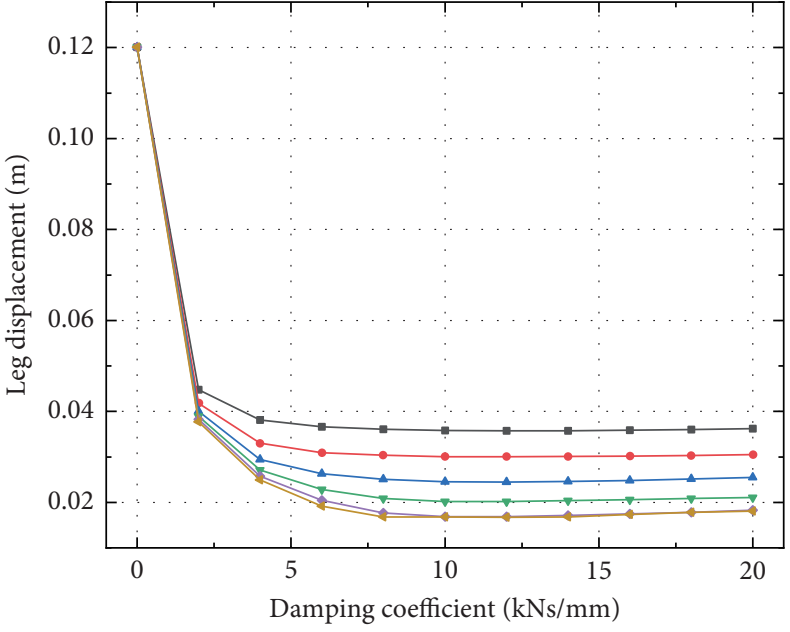

Struct stiffness coefficient $(\mathrm{kN} / \mathrm{mm})$

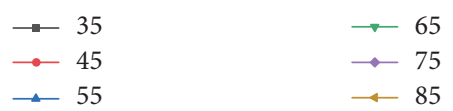
- -35
$\longrightarrow 65$
$\rightarrow 75$
$\longrightarrow$
$\longrightarrow \quad 55$
$\longleftarrow 85$
$\longrightarrow 55$

(b)

(a)

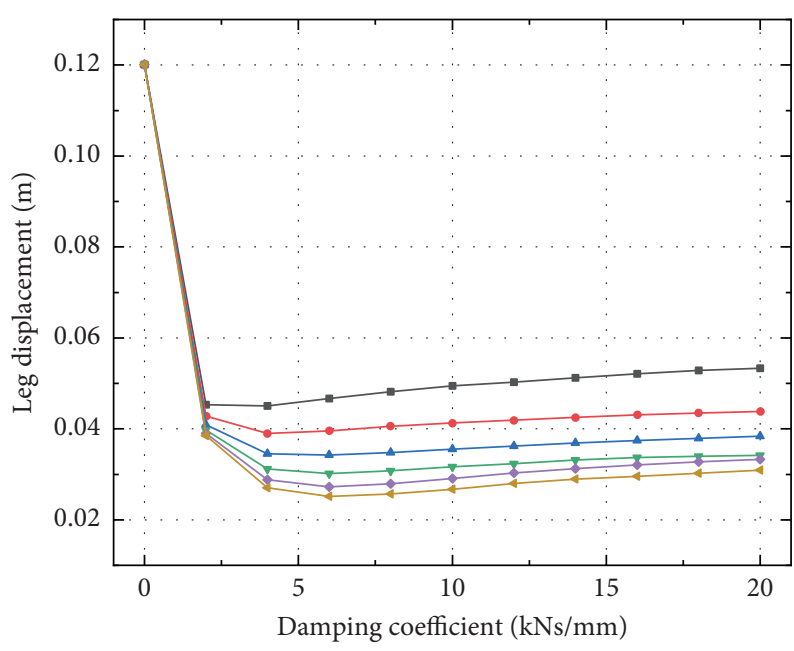

Struct stiffness coefficient $(\mathrm{kN} / \mathrm{mm})$

$\begin{array}{ll}\longrightarrow 35 & \rightarrow 65 \\ \rightarrow 45 & \rightarrow 75 \\ -55 & \multimap 85\end{array}$

(c)

Figure 15: Maximum lateral LDR under ETA50g02 acceleration function.

Figure 15(a). However, the impact of the structure stiffness coefficient plays a more important role than that in Figure 15(a). With the increase of structure stiffness coefficient, the lateral leg displacement decreases. There is a different phenomenon in Figure 15(c) compared to the above two figures. The lateral leg deformation increases with the 


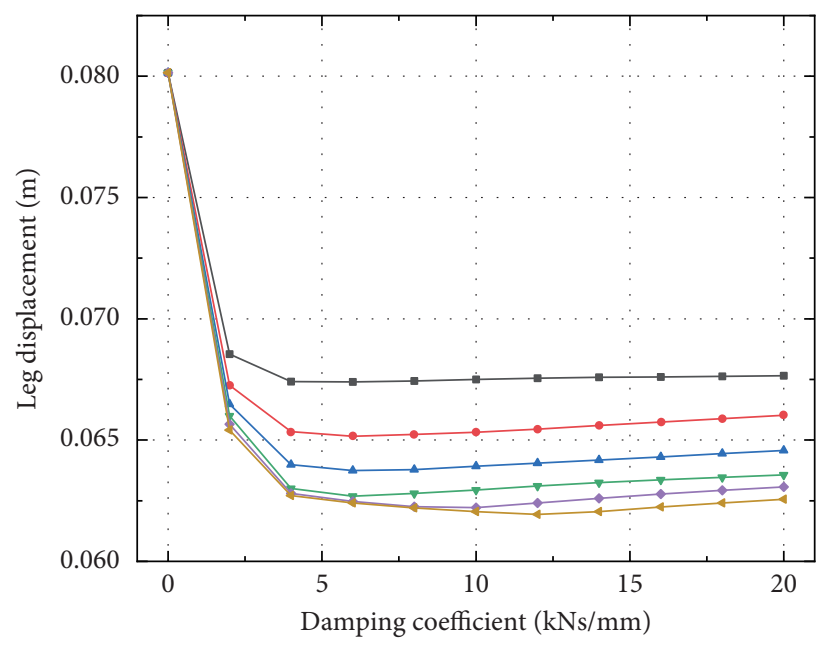

Struct stiffness coefficient $(\mathrm{kN} / \mathrm{mm})$

$\begin{array}{ll}-35 & \longrightarrow 65 \\ \longrightarrow-45 & \longrightarrow 75 \\ -55 & \longrightarrow 85\end{array}$

(a)

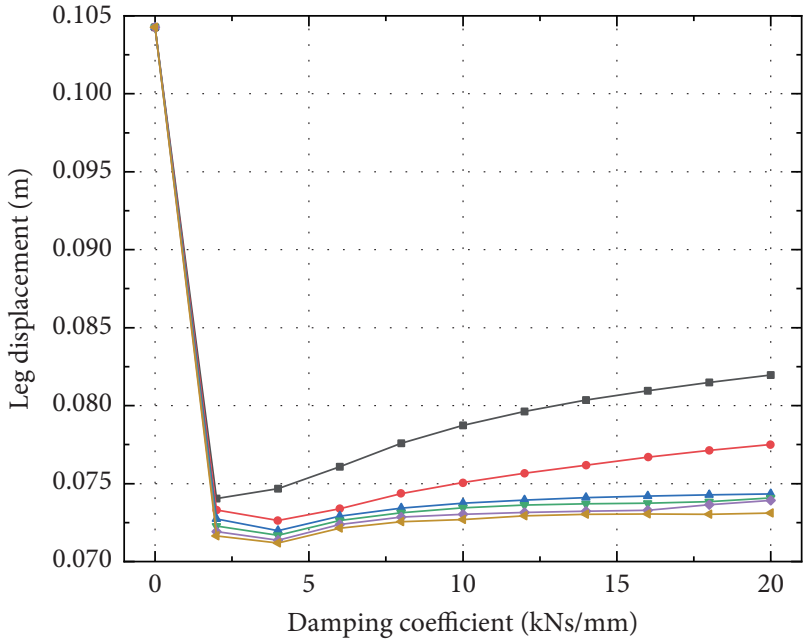

Struct stiffness coefficient $(\mathrm{kN} / \mathrm{mm})$

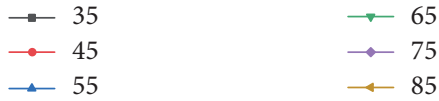

(b)

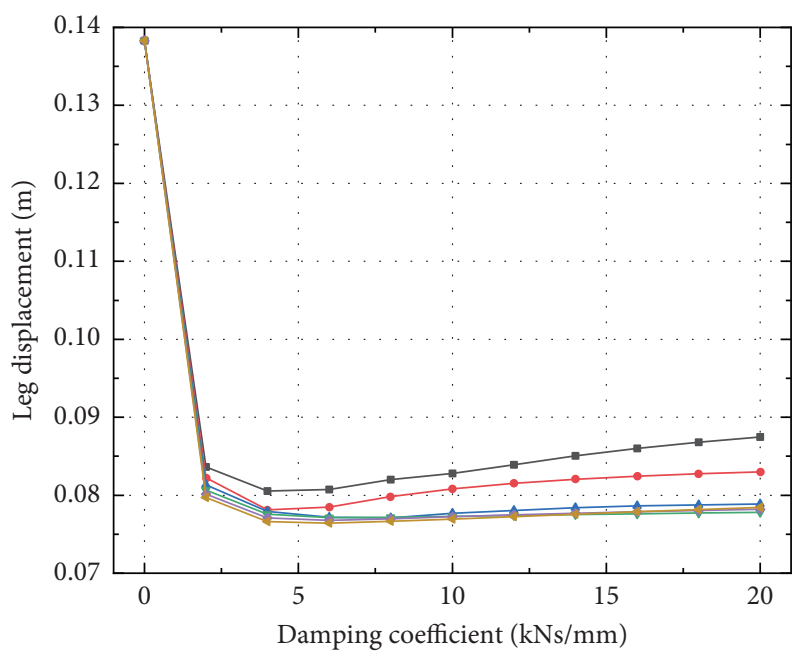

Struct stiffness coefficient $(\mathrm{kN} / \mathrm{mm})$

$\begin{array}{ll}\because 35 & \rightarrow 65 \\ \rightarrow 45 & \rightarrow 75 \\ \longrightarrow 55 & \multimap 85\end{array}$

(c)

FIgURE 16: Maximum vertical LDR under ETA50g02 acceleration function.

raising of the damping coefficient when $C_{D}>5 \mathrm{Ns} / \mathrm{m}$. In other words, when the damping coefficient is greater than $5 \mathrm{Ns} / \mathrm{m}$, the seismic ability of the damping device declines. This situation happens due to the gantry crane experiencing 30 seconds of intensifying ground motion. Therefore, to achieve a better energy dissipation of the damping device, $C_{D}$ should equal to $6 \mathrm{Ns} / \mathrm{m}$, and the structure stiffness coefficient should choose $65 \mathrm{~N} / \mathrm{m}$.

Figure 16 shows the leg deformation of the gantry crane when the duration time $t=10 \mathrm{~s}, 20 \mathrm{~s}$, and $30 \mathrm{~s}$, respectively, and the seismic excitation is in the $Y$ direction. When $t=10 \mathrm{~s}$, the vertical displacement of midspan reduces with the raise of structure stiffness coefficient. On the contrary, the vertical displacement decreases in line with the damping coefficient. When $t=20 \mathrm{~s}$ and $30 \mathrm{~s}$, the vertical displacement increases with the raising of the damping coefficient when $C_{D}>6 \mathrm{Ns} / \mathrm{m}$. In other words, when the damping coefficient is greater than $6 \mathrm{Ns} / \mathrm{m}$, the seismic ability of the damping device declines. In summary, Cd should equal to $6 \mathrm{Ns} / \mathrm{m}$, and structure stiffness coefficient should choose $65 \mathrm{kN} / \mathrm{mm}$ to reduce the vertical displacement efficiently and economically. Combining the two above conclusions, the 
Table 5: Aseismic ratio of viscous dampers at three typical times.

\begin{tabular}{lcccc}
\hline Damage index & Time $(\mathrm{s})$ & $x_{1}(\%)$ & $x_{2}(\%)$ & $\chi(\%)$ \\
\hline \multirow{3}{*}{ Lateral LDR } & 10 & 0.37 & 0.05 & 87 \\
& 20 & 0.8 & 0.07 & 92 \\
& 30 & 0.8 & 0.09 & 89 \\
\hline \multirow{3}{*}{ Vertical LDR } & 10 & 0.53 & 0.18 & 66 \\
& 20 & 0.7 & 0.21 & 70 \\
& 30 & 0.92 & 0.22 & 76 \\
\hline
\end{tabular}

coefficients of the damping device should choose $65 \mathrm{~N} / \mathrm{m}$ and $6 \mathrm{Ns} / \mathrm{m}$, respectively.

To investigate the effect of the viscous dampers more specifically, the aseismic ratio $(\chi)$ is defined to the quantitative analysis as follows: $\chi=\left|x_{1}-x_{2}\right| x_{1} \mid$, where $x_{1}$ means the maximum LDR of the gantry crane without viscous dampers and $x_{2}$ means the maximum LDR of the gantry crane with viscous dampers.

As can be seen in Table 5, the damping strategy proposed in this paper can vastly reduce the displacement of the structure, and the aseismic ratio is up to $92 \%$ in the lateral LDR. Comparing the aseismic ratio of the lateral LDR and the vertical LDR, it is obvious that the values of the vertical LDR are smaller than those of the lateral LDR. This means the horizontal seismic capability of damping devices is better than the vertical seismic capability.

\section{Conclusions}

In this paper, a set of three ET acceleration functions (ETA50g01-03) is utilized to assess the seismic performance of a typical gantry crane. The average ET curve from three ETAFs is utilized to evaluate the dynamic response of the structure. A specified demand measure $(\mathrm{DM})$ is used to evaluate the structure performance quantificationally. The results obtained in ET analysis are compared with those in the IDA analysis. Then, the most critical seismic incident angle is studied to achieve a better understanding of the structural characteristics. Finally, the feasibility and influence of viscous dampers are discussed. The conclusions drawn from this research are summarized below:

(1) The seismic response obtained by the ET procedure is consistent with the results achieved from the IDA analysis while much less computational effort is required. Therefore, the ETA method is proved to be receivable in analyzing the seismic performance of gantry crane with the same level of error from the IDA method;

(2) The average equivalent time of the gantry crane at different limit states is $5.10 \mathrm{~s}(\mathrm{SA}), 11.32 \mathrm{~s}$ (DC), and $26.66 \mathrm{~s}(\mathrm{CP})$, respectively, considering the ET curves with a factor of 2 .

(3) Seismic incident angle plays an important role in evaluating the seismic performance of gantry cranes. The dangerous incident angle is dispersive, but in most situations, the trolley travel direction has the highest seismic demand;
(4) The viscous dampers are used to improve the gantry crane's seismic capacity based on the theory of energy dissipation. And the simulation data demonstrate that the shock absorption strategy utilized in this paper has a significant effect on reducing the structural deformation up to $92 \%$ of the decline.

\section{Data Availability}

Data used to support the findings of this study are currently under embargo while the research findings are commercialized. Requests for data ( 6 months) after the publication of this article will be considered by the corresponding author.

\section{Conflicts of Interest}

The authors declare that there are no potential conflicts of interest.

\section{Acknowledgments}

The research for this paper was supported partially by the Science and Technology Plan of Sichuan Science and Technology Department (no. 2019YJ0243), the National Science Foundation of China (nos. 52178169, 51675450, and 51308465), and the Postdoctoral Science Foundation of China (no. 2015M580031). The authors would like to express their sincere gratitude to all the sponsors for their financial support.

\section{References}

[1] M. Karabulut and M. E. Kartal, "Earthquake response of roller compacted concrete dams including galleries," Structural Engineering \& Mechanics, vol. 72, no. 2, pp. 1-13, 2019.

[2] H.-Y. Jia, D.-Y. Zhang, S.-X. Zheng, W.-C. Xie, and M. D. Pandey, "Local site effects on a high-pier railway bridge under tridirectional spatial excitations: nonstationary stochastic analysis," Soil Dynamics and Earthquake Engineering, vol. 52, pp. 55-69, 2013.

[3] H.-Y. Jia, X.-L. Lan, S.-X. Zheng, L.-P. Li, and C.-Q. Liu, "Assessment on required separation length between adjacent bridge segments to avoid pounding," Soil Dynamics and Earthquake Engineering, vol. 120, pp. 398-407, 2019.

[4] L. D. Jacobs, B. D. Kosbab, R. T. Leon, and R. DesRoches, "Seismic behavior of a jumbo container crane including uplift," Earthquake Spectra, vol. 27, no. 3, 2011.

[5] B. D. Kosbab, R. DesRoches, and R. T. Leon, Seismic Fragility of Jumbo Port Container Cranes, American Society of Civil Engineers, Jacksonville, FL, USA, 2010.

[6] Q. Tran, J. Huh, V. Nguyen, C. Kang, J.-H. Ahn, and I.-J. Park, "Sensitivity analysis for ship-to-shore container crane design," Applied Sciences, vol. 8, no. 9, p. 1667, 2018.

[7] Q. H. Tran, J. Huh, V. B. Nguyen, A. Haldar, C. Kang, and K. M. Hwang, "Comparative study of nonlinear static and time-history analyses of typical Korean sts container cranes," Advances in Civil Engineering, vol. 2018, Article ID 2176894, 13 pages, 2018.

[8] A. Sagirli and C. O. Azeloglu, "Investigation of the dynamic behaviors of cranes under seismic effects with theoretical and 
experimental study," Advanced Materials Research, vol. 445, p. 6, 2012.

[9] H. Yazici, C. O. Azeloglu, and I. B. Kucukdemiral, "Active vibration control of container cranes against earthquake by the use of delay-dependent Ho controller under consideration of actuator saturation," Journal of Low Frequency Noise, Vibration and Active Control, vol. 33, no. 3, pp. 289-316, 2014.

[10] C. O. Azeloglu and A. Sagirli, "Active vibration control of container cranes against earthquake by the use of lmi based mixed state-feedback controller," Shock and Vibration, vol. 2015, Article ID 589289, 13 pages, 2015.

[11] C. O. Azeloglu, A. Sagirli, and A. Edincliler, "Vibration mitigation of nonlinear crane system against earthquake excitations with the self-tuning fuzzy logic pid controller," Nonlinear Dynamics, vol. 84, no. 4, pp. 1915-1928, 2016.

[12] Q. Peng, W. Cheng, H. Jia, and P. Guo, "Fragility analysis of gantry crane subjected to near-field ground motions," Applied Sciences, vol. 10, no. 12, p. 4219, 2020.

[13] H. T. Riahi and H. E. Estekanchi, "Seismic assessment of steel frames with the endurance time method," Journal of Constructional Steel Research, vol. 66, no. 6, pp. 780-792, 2010.

[14] M. A. Hariri-Ardebili, S. Sattar, and H. E. Estekanchi, "Performance-based seismic assessment of steel frames using endurance time analysis," Engineering Structures, vol. 69, pp. 216-234, 2014.

[15] D.-Y. Zhang, H.-Y. Jia, S.-X. Zheng, W.-C. Xie, and M. D. Pandey, "A highly efficient and accurate stochastic seismic analysis approach for structures under tridirectional nonstationary multiple excitations," Computers \& Structures, vol. 145 , pp. 23-35, 2014.

[16] S. K. Ramamoorthy, P. Gardoni, and J. M. Bracci, "Probabilistic demand models and fragility curves for reinforced concrete frames," Journal of Structural Engineering, vol. 132, no. 10, pp. 1563-1572, 2006.

[17] M. A. Dastan Diznab, H. Mehdigholi, and M. S. Seif, "Seismic performance assessment of fixed offshore structures by endurance time method," Ships and Offshore Structures, vol. 14, no. 7, pp. 709-722, 2019.

[18] A. H. Deringöl and E. M. Güneyisi, "Effect of friction pendulum bearing properties on behaviour of buildings subjected to seismic loads," Soil Dynamics and Earthquake Engineering, vol. 125, Article ID 105746, 2019.

[19] D. Vamvatsikos and C. A. Cornell, "Incremental dynamic analysis," Earthquake Engineering \& Structural Dynamics, vol. 31, no. 3, pp. 491-514, 2002.

[20] D. Vamvatsikos and C. A. Cornell, "Applied incremental dynamic analysis," Earthquake Spectra, vol. 20, no. 2, pp. 523-553, 2004.

[21] H. E. Estekanchi, V. Valamanesh, and A. Vafai, "Application of endurance time method in linear seismic analysis," Engineering Structures, vol. 29, no. 10, pp. 2551-2562, 2007.

[22] H. E. Estekanchi, H. T. Riahi, and A. Vafai, "Application of endurance time method in seismic assessment of steel frames," Engineering Structures, vol. 33, no. 9, pp. 2535-2546, 2011.

[23] H. E. Estekanchi and M. Alembagheri, "Seismic analysis of steel liquid storage tanks by endurance time method," ThinWalled Structures, vol. 50, no. 1, pp. 14-23, 2012.

[24] M. A. Foyouzat and H. E. Estekanchi, "Application of rigidperfectly plastic spectra in improved seismic response assessment by endurance time method," Engineering Structures, vol. 111, pp. 24-35, 2016.

[25] Y. J. Park, A. S. Ang, and Y. K. Wen, "Seismic damage analysis and damage-limiting design of rc buildings," Techical Report,
University of Illinois Engineering Experiment Station, Urbana, IL, USA, 1984.

[26] Y. Bozorgnia and V. Bertero, Evaluation of Damage Potential of Recorded Earthquake Ground Motion, Seismolgical Research Letters, Albany, CA, USA, 2001.

[27] H. Krawinkler and M. Zohrei, "Cumulative damage in steel structures subjected to earthquake ground motions," Computers \& Structures, vol. 16, no. 1-4, pp. 531-541, 1983.

[28] H. E. Estekanchi, K. Arjomandi, and A. Vafai, "Estimating structural damage of steel moment frames by endurance time method," Journal of Constructional Steel Research, vol. 64, no. 2, pp. 145-155, 2008.

[29] Ministry of Housing and Urban-Rural Development of the People's Republic of China, Code for Seismic Design of Buildings, Ministry of Housing and Urban-Rural Development of the People's Republic of China, Beijing, China, 2010.

[30] E. Tafakori, S. Pourzeynali, and H. E. Estekanchi, "Probabilistic seismic loss estimation via endurance time method," Earthquake Engineering and Engineering Vibration, vol. 16, no. 1, pp. 233-245, 2017.

[31] S. Mazzoni, F. McKenna, M. H. Scott, and G. L. Fenves, Opensees Command Language Manual, Vol. 264, University of California, , Berkeley, CA, USA, 2006.

[32] B. D. Kosbab, Seismic performance evaluation of port container cranes allowed to uplift, Ph.D. thesis, Georgia Institute of Technology, Atlanta, GA, USA, 2010.

[33] D. Wang, G. Wang, Y. Xiong, and J. Hu, "Analysis of nonlinear dynamic second-order effect of a large-scale container crane under seismic excitations," Vibration Engineering and Technology of Machinery, Springer, Berlin, Germany, 2015.

[34] H. R. Jamshidiha and M. Yakhchalian, "New vector-valued intensity measure for predicting the collapse capacity of steel moment resisting frames with viscous dampers," Soil Dynamics and Earthquake Engineering, vol. 125, Article ID 105625, 2019.

[35] Y. Zhang, Q. Li, Y. Zhuge, A. Liu, and W. Zhao, "Experimental study on spatial prefabricated self-centering steel frame with beam-column connections containing bolted web friction devices," Engineering Structures, vol. 195, pp. 1-21, 2019.

[36] F. E. M. Agency, Prestandard and Commentary for the Seismic Rehabilitation of Buildings, American Society of Civil Engineers (ASCE), Reston, VA, USA, 2000.

[37] M. C. Basim and H. E. Estekanchi, "Application of endurance time method in performance-based optimum design of structures," Structural Safety, vol. 56, pp. 52-67, 2015.

[38] A. Otani, K. Nagashima, and J. Suzuki, "Vertical seismic response of overhead crane," Nuclear Engineering and Design, vol. 212, no. 1-3, pp. 211-220, 2002.

[39] A. Sagirli, C. O. Azeloglu, R. Guclu, and H. Yazici, "Selftuning fuzzy logic control of crane structures against earthquake induced vibration," Nonlinear Dynamics, vol. 64, no. 4, pp. 375-384, 2011. 